\title{
Comparison of a Novel Formulation of Abiraterone Acetate vs. the Originator Formulation in Healthy Male Subjects: Two Randomized, Open-Label, Crossover Studies
}

\author{
Ronald Goldwater $^{1} \cdot$ Azra Hussaini $^{1} \cdot$ Bill Bosch $^{2} \cdot$ Paul Nemeth $^{2}$
}

Published online: 19 April 2017

(C) The Author(s) 2017. This article is an open access publication

\begin{abstract}
Background and Objective Abiraterone acetate is approved for the treatment of metastatic castration-resistant prostate cancer. The originator abiraterone acetate (OAA) formulation is poorly absorbed and exhibits large pharmacokinetic variability in abiraterone exposure. Abiraterone acetate fine particle (AAFP) is a proprietary formulation (using SoluMatrix Fine Particle Technol$\mathrm{ogy}^{\mathrm{TM}}$ ) designed to increase the oral bioavailability of abiraterone acetate. Here, we report on two phase I studies in healthy male subjects aged $18-50$ years.

Methods In Study 101, 20 subjects were randomized in a crossover design to single doses of AAFP 100, 200, or $400 \mathrm{mg}$ or OAA $1000 \mathrm{mg}$ taken orally under fasting conditions. Results suggested that AAFP $500 \mathrm{mg}$ would be bioequivalent to OAA $1000 \mathrm{mg}$ in the fasted state. To confirm the bioequivalence hypothesis and to further expand the AAFP dose range, in Study 102, 36 subjects were randomized in a crossover design to single doses of AAFP 125,500 , or $625 \mathrm{mg}$ or OAA $1000 \mathrm{mg}$. Both studies included a 7-day washout period between administrations. Results Dose-dependent increases in the area under the plasma concentration-time curve and maximum plasma concentration with AAFP were observed in both studies. The AAFP 500-mg bioavailability relative to OAA
\end{abstract}

Electronic supplementary material The online version of this article (doi:10.1007/s40262-017-0536-2) contains supplementary material, which is available to authorized users.

Paul Nemeth

pnemeth@churchillpharma.com

PAREXEL Early Phase Clinical Unit, Baltimore, MD, USA

2 Churchill Pharmaceuticals LLC, 3602 Horizon Drive, Suite 160, King of Prussia, PA 19406, USA
$1000 \mathrm{mg}$ measured by the geometric mean ratio for area under the plasma concentration-time curve from time zero to the time of the last quantifiable concentration was $93.4 \%$ (90\% confidence interval 85.3-102.4), area under the plasma concentration-time curve from time zero to infinity was $91.0 \%$ (90\% confidence interval 83.3-99.4), and maximum plasma concentration was $99.8 \%$ (90\% confidence interval 86.3-115.5). Dose proportionality was seen across all AAFP dose levels (100-625 mg). Abiraterone acetate fine particle was found to be safe and well tolerated in this study.

Conclusion Abiraterone acetate fine particle $500 \mathrm{mg}$ was demonstrated to be bioequivalent to OAA $1000 \mathrm{mg}$ in healthy volunteers under fasted conditions.

\section{Key Points}

Abiraterone acetate fine particle is a proprietary formulation (using SoluMatrix Fine Particle Technology ${ }^{\mathrm{TM}}$ ) that has enhanced dissolution properties designed to increase the oral bioavailability of abiraterone acetate relative to the originator abiraterone acetate formulation.

Abiraterone acetate fine particle displayed dose proportionality over the wide range of doses (100-625 mg) tested under fasted conditions.

The 500-mg dose of abiraterone acetate fine particle was bioequivalent to the $1000-\mathrm{mg}$ dose of originator abiraterone acetate based on the $90 \%$ confidence interval of the geometric mean ratio of the area under the plasma concentration-time curve and maximum plasma concentration parameters. 


\section{Introduction}

Prostate cancer is the second most common cancer in men [1], with an estimated 180,890 new cases of prostate cancer projected for 2016 in USA and 26,120 projected deaths [2]. Androgen activity affects the development of prostate cancer, a finding that has led to therapies that target the synthesis and signaling of these steroid hormones [3]. Once prostate cancer has advanced to metastatic disease, androgen deprivation therapy is employed. However, drug resistance is of serious concern, as further progression of prostate cancer can lead to the lethal phenotype of castration-resistant prostate cancer [4].

Abiraterone is a selective inhibitor of $17 \alpha$-hydroxylase/ C17, 20-lyase, a key enzyme in androgen synthesis, which reduces the level of circulating androgens [5]. Abiraterone acetate is a prodrug for abiraterone. Studies of the originator abiraterone acetate (OAA) tablets $\left(\mathrm{Zytiga}^{\circledR}\right.$ ) were conducted in healthy subjects and in patients with prostate cancer. Phase I dose-escalation studies of OAA in prostate cancer patients indicated that it is generally safe and well tolerated and has antitumor activity at tested doses (250-2000 mg) [6]. Abiraterone exposure was observed to approach saturation and not significantly increase beyond the 1000-mg dose [7]. Large variability in abiraterone exposure has also been observed in healthy subjects dosed with single doses of OAA [8].

SoluMatrix Fine Particle Technology ${ }^{\mathrm{TM}}$ is intended to increase the in vivo dissolution rate of lipophilic, poorly water-soluble active pharmaceutical ingredients and to improve the low oral bioavailability, high pharmacokinetic variability, and food effects often associated with these types of compounds. In the present study, the pharmacokinetic characteristics and safety profile of abiraterone acetate fine particle (AAFP) tablet formulated using SoluMatrix Fine Particle Technology ${ }^{\mathrm{TM}}$ were compared with the reference drug, OAA, in healthy male adults.

\section{Methods}

\subsection{Study Population}

Normal healthy male subjects aged $18-50$ years with a body mass index between 18 and $30 \mathrm{~kg} / \mathrm{m}^{2}$ who met additional inclusion/exclusion criteria were enrolled in the studies. Subjects were in good health based on physical examination and laboratory test results. No concomitant medication use was noted for any subject during the study. Subjects with a recent history (i.e., within the previous year) of mental illness, drug addiction or abuse, or alcoholism, or the use of any drugs known to induce or inhibit hepatic drug metabolism within 30 days of planned dosing were excluded. All enrolled subjects were negative for abused drugs and alcohol at screening and in repeat testing the day prior to dosing of the investigational medical product.

\subsection{Study Design}

Study 101 and Study 102 were both single-dose, randomized, open-label, four-period, four-treatment crossover studies performed under fasted conditions, and they were conducted at a single center in USA (PAREXEL International Early Phase Clinical Unit, Baltimore, MD, USA). The test drugs in this study were administered orally. Study 101 was conducted between 11 February, 2014, and 7 April, 2014. Study 102 was conducted between 10 October, 2014, and 9 December, 2014. For Study $101(n=20)$ and Study $102(n=36)$, the subjects met all the eligibility criteria and were subsequently included and randomized in the study. All subjects provided written informed consent and the study was approved by the Aspire Institutional Review Board (Santee, CA, USA).

Study 101 was divided into a screening phase of up to 28 days followed by four sequential 1-day treatment periods, with an intervening 7-day washout period scheduled between administrations. The total study duration was approximately 52 days, including the screening period. The AAFP tablets were given as single doses of 100, 200, and $400 \mathrm{mg}$, and OAA was given as a single dose of $1000 \mathrm{mg}$.

Study 102 was divided into a screening period of up to 28 days followed by four sequential 1-day treatment periods, with an intervening 7-day washout period between administrations. The maximum study duration for each subject was approximately 54 days. The AAFP $125-\mathrm{mg}$ tablets were given as single doses of 125,500 , and $625 \mathrm{mg}$, and OAA was given as a single dose of $1000 \mathrm{mg}$.

For both studies, enrolled subjects were allocated randomization numbers sequentially and then randomly allocated to sequence groups according to a pre-generated randomization schedule. A single standard dose of OAA $1000 \mathrm{mg}(4 \times 250$-mg tablets $)$ was administered to subjects. All abiraterone acetate doses were given after an overnight fast, and no food was consumed until $4 \mathrm{~h}$ after dosing. There was no placebo control group for either study because each subject served as his own control.

The AAFP tablets were manufactured by Mayne Pharma Group Ltd for Churchill Pharmaceuticals LLC. SoluMatrix Fine Particle Technology ${ }^{\mathrm{TM}}$ is licensed from iCeutica, Inc. to Churchill Pharmaceuticals LLC for the use of AAFP. The OAA tablets were obtained commercially. 


\subsection{Pharmacokinetic Evaluation Criteria}

For the determination of abiraterone concentrations, blood samples were collected prior to dosing ( $0 \mathrm{~h}$ for Study 101 , $-0.75 \mathrm{~h}$ for Study 102) and at $0.25,0.50,1.00,1.50,2.00$, $3.00,4.00,6.00,8.00,12.00,24.00$, and 48.00 h post-dose. For Study 102, blood samples were also collected at $72.00 \mathrm{~h}$ post-dose.

\subsection{Blood Sample Collection and Bioanalytical Assay}

Blood samples (approximately $6 \mathrm{~mL}$ ) for pharmacokinetic analyses were collected into 6-mL tripotassiumethylenediaminetetraacetic acid-containing tubes. Blood samples were immediately placed on ice. Plasma was separated by centrifugation at $4{ }^{\circ} \mathrm{C}$, transferred to appropriately labeled polypropylene specimen containers, frozen at $-20{ }^{\circ} \mathrm{C}$ within $1 \mathrm{~h}$ of collection, and then stored at $-20{ }^{\circ} \mathrm{C}$. Samples were shipped on dry ice to the bioanalytical laboratory for analysis. Plasma samples were analyzed for abiraterone concentrations using a validated bioanalytical assay (Sannova Analytical, Somerset, NJ, USA).

The samples were extracted using the liquid-liquid extraction method and analyzed using reverse-phase liquid chromatography. The analytes were detected using tandem mass spectrometry. The lower limit of quantitation for abiraterone was $0.651 \mathrm{ng} / \mathrm{mL}$. The upper limit of quantitation for abiraterone was $203.519 \mathrm{ng} / \mathrm{mL}$. A calibration curve consisting of two control blanks, two zero standards, and ten non-zero calibration standards covering a concentration range of $0.651-203.519 \mathrm{ng} / \mathrm{mL}$ for abiraterone were analyzed with every sample batch. Quality control standards for abiraterone were also analyzed with every sample batch. Internal standard peak area ratio values were used to set up the calibration curve and to determine quality control and unknown sample concentrations. Linear regression for abiraterone was used to obtain the best fit of the data for the calibration curve.

\subsection{Pharmacokinetic Analysis}

The following plasma pharmacokinetic parameters were determined: the area under the plasma concentration-time curve (AUC) from time zero to the time $(t)$ of the last quantifiable concentration $\left(C_{t}\right)$ [AUC $\left.\mathrm{AU-t}_{t}\right]$, as calculated by the linear trapezoidal method; AUC from time zero to infinity $\left(\mathrm{AUC}_{0-\infty}\right)$; maximum measured plasma concentration $\left(C_{\max }\right)$; time to maximum measured plasma concentration $\left(t_{\max }\right)$; apparent elimination rate constant $\left(K_{\mathrm{e}}\right)$ as determined by linear regression of the terminal points of the log-linear concentration-time curve; and apparent elimination half-life $\left(t_{1 / 2}\right)$ calculated as $\log _{\mathrm{e}}(2) / K_{\mathrm{e}}$ or $0.693 /$ $K_{\mathrm{e}}$.

\subsection{Safety Assessments}

All subjects who received at least one dose of abiraterone acetate were included in the safety population. Assessments included physical examinations, recording of vital signs, electrocardiography, clinical laboratory testing (hematology, biochemistry, and urinalysis), and adverse event (AE) assessments. Concomitant medications were assessed throughout the clinical study.

\subsection{Sample Size}

For Study 101, previous studies in healthy subjects indicated that following a single $1000-\mathrm{mg}$ dose of OAA, the $\mathrm{AUC}_{0-\infty}$ was approximately $500 \mathrm{ng} \cdot \mathrm{h} / \mathrm{mL}$ with a standard deviation (SD) of approximately 300 . It was estimated that 18 subjects would be able to provide a statistical power of $90 \%$ to detect a $50 \%$ difference in the reference mean between a test and reference dose at the 0.05 level (twosided) using a paired $t$ test. The clinical study planned to randomize 20 subjects for the four-way crossover design without replacement.

For Study 102, results from Study 101 indicated that the estimated within-subject between-formulation $\sigma$ (log scale) was about 0.08 for AUC parameters. Assuming that the true AUC mean of a test treatment was within the $95 \%$ region of the reference, a sample size of 32 subjects or more with a two-way analysis of variance (ANOVA) model for bioequivalence assessment would have at least $80 \%$ power to reject the null hypothesis of bio-inequivalence at the level of 0.05 . Taking dropouts into consideration, 36 subjects were planned to be randomized and dosed without replacement.

\subsection{Statistical Analysis}

A parametric general linear model was applied to the pharmacokinetic parameters of AUC, $C_{\max }, t_{\max }, t_{1 / 2}$, and $K_{\mathrm{e}}$. An ANOVA for a crossover design was used to examine the differences among the doses $(100,200$, and $400 \mathrm{mg}$ AAFP and $1000 \mathrm{mg}$ OAA in Study 101; 125, 500, and $625 \mathrm{mg}$ AAFP and $1000 \mathrm{mg}$ OAA in Study 102) under fasted conditions. The AUC and $C_{\max }$ parameters of AAFP 500 and $625 \mathrm{mg}$ and OAA $1000 \mathrm{mg}$ were compared and analyzed on a natural logarithm scale using a three-way ANOVA model with sequence, subject within sequence, treatment, and period as the classification variables to assess relative bioavailability in Study 102 using the bioequivalence approach. To determine 
bioequivalence, AUC and $C_{\max }$ parameters were analyzed on a $\log$ scale. The two one-sided $t$ test hypotheses were tested at the 0.05 level by constructing a $90 \%$ confidence interval $(\mathrm{CI})$ for the geometric mean ratio. Bioequivalence was concluded if the $90 \%$ CIs of the ratios were within 0.80-1.25 for AUC and $C_{\max }$ parameters. For dose proportionality, $C_{\max }$ and AUC parameters were examined among AAFP doses ranging from 100 to $625 \mathrm{mg}$ for both studies pooled, using a power model, $P=a \times \operatorname{Dose}^{b}$, where $P$ represents $C_{\max }$ or AUC, and $a$ and $b$ are constants. A value of $b$ approximately equal to 1 was used to establish linearity or dose proportionality over the dose range under study.

\section{Results}

\subsection{Subject Baseline Characteristics and Disposition}

Demographic characteristics for both studies are shown in Table 1. For Study 101, 20 subjects met all the eligibility criteria and were subsequently included and randomized to one of the four dose schedules. Seventeen of the randomized subjects $(85 \%)$ received all four doses, one subject received three doses, and two subjects received two doses of abiraterone acetate.

For Study 102, 36 subjects met all eligibility criteria and were included and randomized to one of the four dose schedules. Thirty-three randomized subjects (91.7\%) received all four doses, one subject received three doses, and two subjects received two doses of abiraterone acetate. Minor protocol deviations were recorded for subjects in both studies during the course of the assessments, but they did not affect the outcomes or interpretations of the study results.

Table 1 Summary of demographic and baseline characteristics

\begin{tabular}{lll}
\hline & Study 101 & Study 102 \\
\hline Number of subjects & 20 & 36 \\
Mean age (SD), years & $33.4(8.01)$ & $34.5(8.27)$ \\
Mean weight (SD), kg & $81.24(11.884)$ & $82.27(10.245)$ \\
Mean height (SD), cm & $177.1(8.05)$ & $177.3(7.55)$ \\
Mean BMI (SD), kg/m ${ }^{2}$ & $25.82(2.691)$ & $26.14(2.504)$ \\
Race, $n(\%)$ & & \\
White & $5(25)$ & $8(22.2)$ \\
African American & $15(75)$ & $26(72.2)$ \\
Other & $0(0)$ & $2(5.6)$ \\
\hline
\end{tabular}

$B M I$ body mass index, $S D$ standard deviation

\subsection{Pharmacokinetic Parameters of AAFP}

\subsubsection{Study 101}

Following administration of AAFP (100, 200, and $400 \mathrm{mg}$ ), plasma concentrations of the drug increased rapidly (Fig. 1a, b). Mean peak concentrations were observed at approximately $1.5-2.0 \mathrm{~h}$ post-dose, followed by a gradual decline at or below the lower limit of quantification by $48 \mathrm{~h}$ post-dose. For OAA $1000 \mathrm{mg}$, concentrations also peaked at $2.0 \mathrm{~h}$ post-dose and were near the lower limit of quantification at $48 \mathrm{~h}$ post-dose.

There was a dose-dependent increase in the AUC and $C_{\max }$ (Table 2). For AAFP 100, 200, and $400 \mathrm{mg}, \mathrm{AUC}_{0-\infty}$ was $74.5,183.3$, and $319.9 \mathrm{ng} \cdot \mathrm{h} / \mathrm{mL}(421.2 \mathrm{ng} \cdot \mathrm{h} / \mathrm{mL}$ for OAA); $\mathrm{AUC}_{0-t}$ was $67.6,170.0$, and $302.9 \mathrm{ng} \cdot \mathrm{h} / \mathrm{mL}$ (387.3 ng.h/mL for OAA); and $C_{\max }$ was $17.3,39.1$, and $65.4 \mathrm{ng} / \mathrm{mL}(79.5 \mathrm{ng} / \mathrm{mL}$ for OAA), respectively. The median $t_{\max }$ for the three AAFP doses ranged from 1.5 to $2.0 \mathrm{~h}\left(2.0 \mathrm{~h}\right.$ for OAA). The mean $t_{1 / 2}$ increased with dose for AAFP and was 4.7, 7.8, and $8.8 \mathrm{~h}$ for the 100-, 200-, and $400-\mathrm{mg}$ doses, respectively (14.5 $\mathrm{h}$ for OAA). Analysis of dose proportionality, using the bioequivalence approach, for AAFP 100- and 400-mg doses compared with the 200-mg dose is shown in Online Resource 1. The drug exposure parameters (AUC and $C_{\max }$ ) for the highest dose of AAFP $(400 \mathrm{mg}$ ) were only $18-24 \%$ below those for OAA $1000 \mathrm{mg}$, suggesting that a single 500-mg dose of AAFP should be bioequivalent to a single 1000-mg dose of OAA under fasted conditions.

\subsubsection{Study 102}

The dose range in Study 102 was expanded to include AAFP 125-, 500-, and 625-mg doses and compared with OAA $1000 \mathrm{mg}$ as a reference. Following a single-dose administration of each of the three doses of AAFP (125, 500 , and $625 \mathrm{mg}$ ), plasma concentrations of abiraterone increased with increasing doses (Fig. $1 \mathrm{c}, \mathrm{d}$ ). The curve for AAFP $500 \mathrm{mg}$ overlapped with the curve for OAA. Peak levels occurred approximately $2 \mathrm{~h}$ post-dose for all doses. This pattern was also observed for individual subjects receiving each dose of AAFP.

Table 3 shows the arithmetic means for $\mathrm{AUC}_{0-\infty}$, which were $112.1,438.02$, and $473.31 \mathrm{ng} \cdot \mathrm{h} / \mathrm{mL}$ for AAFP 125,500 , and $625 \mathrm{mg}$, respectively, compared with $453.2 \mathrm{ng} \cdot \mathrm{h} / \mathrm{mL}$ for OAA $1000 \mathrm{mg}$. The $\mathrm{AUC}_{0-t}$ means were 102.6, 416.2, and $450.2 \mathrm{ng} \cdot \mathrm{h} / \mathrm{mL}$ for AAFP 125,500 , and $625 \mathrm{mg}$, respectively, compared with $415.9 \mathrm{ng} \cdot \mathrm{h} / \mathrm{mL}$ for OAA. Maximum plasma concentration means were 28.2, 84.2, and $100.8 \mathrm{ng} /$ $\mathrm{mL}$ for AAFP 125,500 , and $625 \mathrm{mg}$, respectively, compared with $83.4 \mathrm{ng} / \mathrm{mL}$ for OAA. Comparisons of AUC and $C_{\max }$ values for AAFP 125, 500, and $625 \mathrm{mg}$ and OAA $1000 \mathrm{mg}$ 

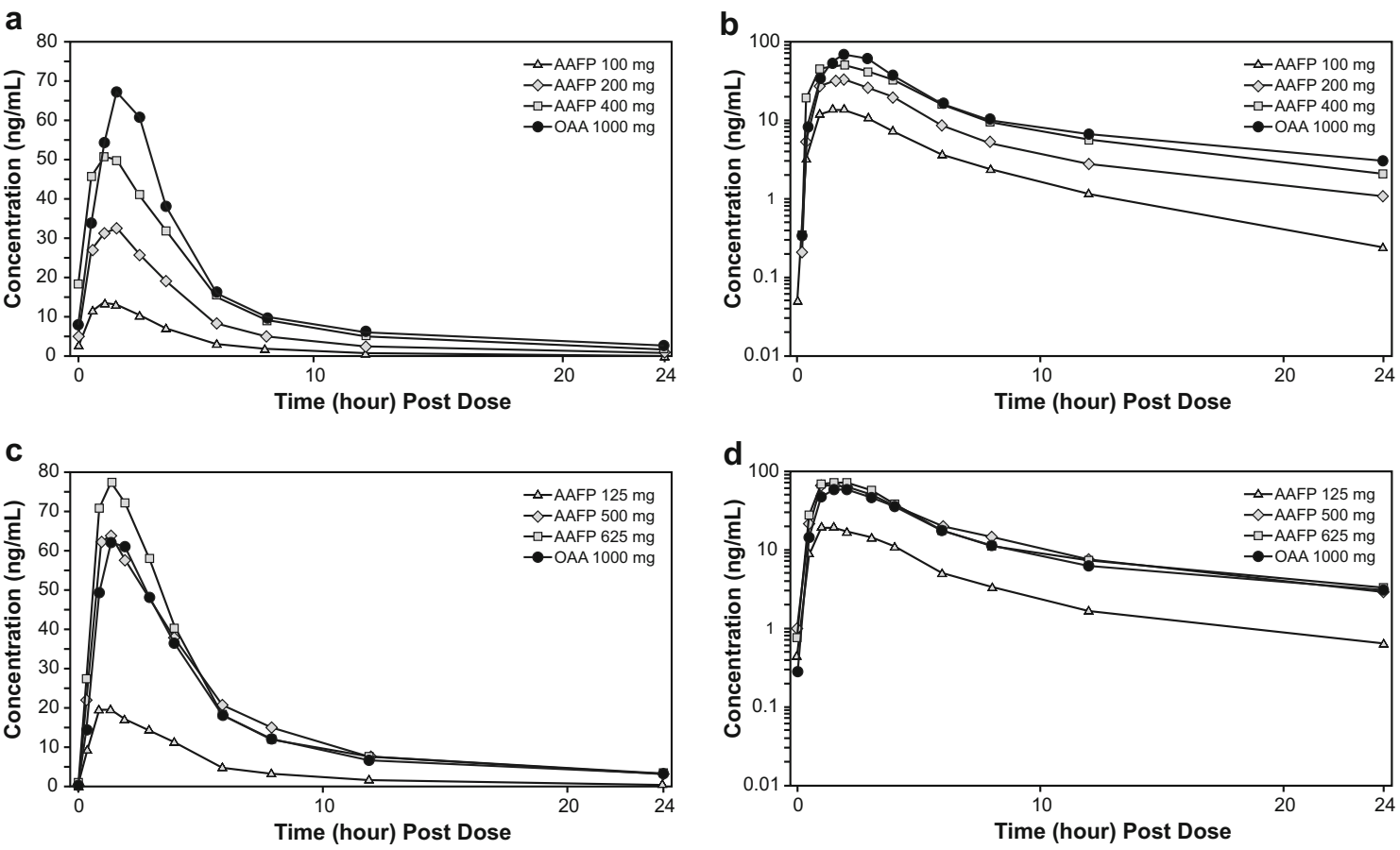

Fig. 1 a Linear scale of mean plasma concentration-time plot by treatment for Study 101. b Semi-logarithmic scale of mean plasma concentration-time profile for Study 101. c Linear scale of mean plasma concentration-time plot by treatment for Study 102. d Semi-

logarithmic scale of mean plasma concentration-time profile for Study 102. $A A F P$ abiraterone acetate fine particle, $O A A$ originator abiraterone acetate

are shown graphically in Fig. 2. The median $t_{\max }$ was similar at $1.5 \mathrm{~h}$ at all AAFP doses compared with $2.0 \mathrm{~h}$ for OAA. The median $t_{\max }$ for both the AAFP 500- and 625-mg doses (Table 3) compared with OAA was not statistically significant (AAFP $500 \mathrm{mg}$ vs. OAA $1000 \mathrm{mg}, P=0.2301$; AAFP $625 \mathrm{mg}$ vs. OAA $1000 \mathrm{mg}, P=0.3041$ ) as determined by the Wilcoxon signed rank test. The elimination half-life for AAFP $500 \mathrm{mg}$ and $625 \mathrm{mg}$ was $14.1 \mathrm{and} 14.5 \mathrm{~h}$, respectively, vs. $20.6 \mathrm{~h}$ for OAA $1000 \mathrm{mg}$. The difference in $t_{1 / 2}$ between AAFP 500 and $625 \mathrm{mg}$ and OAA $1000 \mathrm{mg}$ was statistically significant $(P<0.0001)$ as determined by the Wilcoxon signed rank test.

Bioequivalence analyses of AAFP 500- and 625-mg test doses compared with OAA $1000 \mathrm{mg}$ are shown in Table 4. The relative bioavailability of 500 and $625 \mathrm{mg}$ of AAFP, calculated by the geometric mean ratio of AUC, indicated that a single dose of 500 or $625 \mathrm{mg}$ of AAFP was bioequivalent to a 1000-mg single dose of OAA, based on the predefined bioequivalence criteria of $90 \% \mathrm{CI}$ within $0.80-1.25$. By these same criteria, a single dose of $500 \mathrm{mg}$ of AAFP was also bioequivalent to a single dose of OAA $1000 \mathrm{mg}$ in terms of $C_{\text {max }}$. However, $625 \mathrm{mg}$ of AAFP was not bioequivalent (90\% CI 1.02-1.37) for peak $\left(C_{\max }\right)$ abiraterone exposure.

Analysis of dose proportionality of AAFP, using the bioequivalence approach, is shown in Table 5. Area under the plasma concentration-time curve parameters for AAFP 125 vs. $500 \mathrm{mg}$ fell within the recommended $90 \% \mathrm{CI}$ (0.80-1.25 limit) of the geometric mean ratios for bioequivalence, but $C_{\max }$ did not. However, for AAFP $625 \mathrm{mg}$ vs. $500 \mathrm{mg}$, the $90 \%$ CIs of the geometric mean ratios for both AUC and $C_{\max }$ were within the limits of bioequivalence.

\subsubsection{AAFP Dose Proportionality}

The dose proportionality of AAFP 100-, 125-, 200-, 400-, 500-, and 625-mg doses across Study 101 and Study 102 was evaluated using a power model $\left(P=a \times \operatorname{Dose}^{b}\right)$ of linearity analysis. The results are shown in Table 6 . The findings indicate that constant $b$ was 0.986 (95\% CI $0.864-1.109$ ) for $\mathrm{AUC}_{0-\infty}, 1.015$ (95\% CI $0.888-1.142)$ for $\mathrm{AUC}_{0-t}$, and $0.865(95 \% \mathrm{CI}$ 0.735-0.995) for $C_{\max }$, indicating a high degree of linearity ( $b$ value of approximately 1 ), which suggests dose proportionality of abiraterone in the range of $100-625 \mathrm{mg}$ of AAFP. 
Table 2 Study 101 summary of plasma pharmacokinetic parameters (pharmacokinetic population)

\begin{tabular}{|c|c|c|c|c|c|}
\hline \multirow[t]{2}{*}{ Pharmacokinetic parameter } & \multirow{2}{*}{$\begin{array}{l}\text { Summary statistics } \\
N\end{array}$} & \multicolumn{4}{|c|}{ 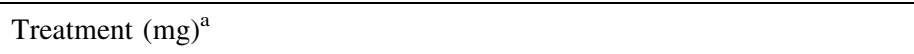 } \\
\hline & & $\begin{array}{l}\text { AAFP } 100 \\
19\end{array}$ & $\begin{array}{l}\text { AAFP } 200 \\
18\end{array}$ & $\begin{array}{l}\text { AAFP } 400 \\
19\end{array}$ & $\begin{array}{l}\text { OAA } 1000 \\
19\end{array}$ \\
\hline \multirow[t]{4}{*}{$\mathrm{AUC}_{0-\infty}(\mathrm{ng} \cdot \mathrm{h} / \mathrm{mL})$} & Mean & 74.49 & 183.34 & 319.92 & 421.23 \\
\hline & SD & 42.22 & 86.70 & 140.74 & 183.83 \\
\hline & $\mathrm{CV} \%$ & 56.68 & 47.29 & 43.99 & 43.64 \\
\hline & Geometric mean & 64.46 & 166.16 & 290.89 & 383.46 \\
\hline \multirow[t]{4}{*}{$\mathrm{AUC}_{0-t}(\mathrm{ng} \cdot \mathrm{h} / \mathrm{mL})$} & Mean & 67.55 & 169.99 & 302.90 & 387.34 \\
\hline & SD & 39.37 & 83.73 & 137.17 & 168.67 \\
\hline & $\mathrm{CV} \%$ & 58.28 & 49.25 & 45.29 & 43.55 \\
\hline & Geometric mean & 57.86 & 152.6 & 273.40 & 352.08 \\
\hline \multirow[t]{4}{*}{$C_{\max }(\mathrm{ng} / \mathrm{mL})$} & Mean & 17.28 & 39.11 & 65.42 & 79.46 \\
\hline & SD & 10.41 & 21.69 & 35.58 & 39.56 \\
\hline & CV\% & 60.29 & 55.46 & 54.39 & 49.78 \\
\hline & Geometric mean & 14.66 & 33.94 & 56.00 & 70.63 \\
\hline \multirow[t]{5}{*}{$t_{\max }(\mathrm{h})$} & Mean & 1.55 & 1.78 & 2.32 & 2.16 \\
\hline & SD & 0.57 & 0.77 & 1.33 & 0.78 \\
\hline & Median & 1.5 & 1.75 & 2 & 2 \\
\hline & CV\% & 37.02 & 43.38 & 57.22 & 36.27 \\
\hline & Geometric mean & 1.45 & 1.64 & 1.99 & 2.03 \\
\hline \multirow[t]{5}{*}{$t_{1 / 2}(\mathrm{~h})$} & Mean & 4.72 & 7.83 & 8.84 & 14.48 \\
\hline & SD & 2.57 & 3.88 & 2.96 & 5.11 \\
\hline & Median & 3.66 & 6.94 & 8.05 & 14.01 \\
\hline & $\mathrm{CV} \%$ & 54.35 & 49.51 & 33.45 & 35.32 \\
\hline & Geometric mean & 4.17 & 7.06 & 8.42 & 13.64 \\
\hline \multirow[t]{4}{*}{$K_{\mathrm{e}}(/ \mathrm{h})$} & Mean & 0.18 & 0.11 & 0.09 & 0.05 \\
\hline & SD & 0.08 & 0.05 & 0.03 & 0.02 \\
\hline & $\mathrm{CV} \%$ & 43.38 & 45.27 & 30.80 & 36.98 \\
\hline & Geometric mean & 0.17 & 0.10 & 0.08 & 0.05 \\
\hline
\end{tabular}

$A A F P$ abiraterone acetate fine particle, $A U C_{0-\infty}$ area under the plasma concentration-time curve from time zero to infinity, $A U C_{0-t}$ area under the plasma concentration-time curve from time zero to the time of the last quantifiable concentration, $C_{\max }$ maximum plasma concentration, $C V \%$ coefficient of variation expressed as percent, $K_{e}$ apparent elimination rate constant, $N$ number of subjects included in the pharmacokinetic population for each treatment, $O A A$ originator abiraterone acetate, $S D$ standard deviation, $t_{1 / 2}$ elimination half-life, $t_{\max }$ time to maximum plasma concentration

a AAFP $100 \mathrm{mg}(1 \times 100 \mathrm{mg}), 200 \mathrm{mg}(2 \times 100 \mathrm{mg}), 400 \mathrm{mg}(4 \times 100 \mathrm{mg})$, and OAA $1000 \mathrm{mg}(4 \times 250 \mathrm{mg})$ under fasted conditions

\subsection{Safety}

Treatment-emergent AEs related to either AAFP or OAA were mostly mild in intensity (grade 1) for both studies. However, three subjects experienced moderate-intensity (grade 2) AEs (upper respiratory tract infection, headache, and increased transaminase). All treatment-emergent AEs were resolved by the end of the studies, with the exception of one subject who was discontinued from the study because of neutropenia following a dose of the OAA. The outcome for this subject was unknown. There were no serious AEs or deaths during the studies.

\section{Discussion}

The main finding in this report was that a single dose of AAFP $500 \mathrm{mg}$ was bioequivalent to the recommended dose of OAA $1000 \mathrm{mg}$ [7], thus demonstrating that a $50 \%$ lower dose of AAFP produces equivalent pharmacokinetics as OAA. The AAFP formulation displayed dose proportionality over the wide range of doses (100-625 mg) that were tested. With regard to drug exposure, the relative bioavailability of a single AAFP 500-mg dose under fasted conditions was approximately $90-100 \%$ compared with a single dose of OAA $1000 \mathrm{mg}$. Furthermore, the AAFP 
Table 3 Study 102 summary of plasma pharmacokinetic parameters (pharmacokinetic population)

\begin{tabular}{|c|c|c|c|c|c|}
\hline \multirow[t]{2}{*}{ Pharmacokinetic parameter } & \multirow{2}{*}{$\begin{array}{l}\text { Summary statistics } \\
N\end{array}$} & \multicolumn{4}{|c|}{ Treatment $(\mathrm{mg})^{\mathrm{a}}$} \\
\hline & & $\begin{array}{l}\text { AAFP } 125 \\
33\end{array}$ & $\begin{array}{l}\text { AAFP } 500 \\
34\end{array}$ & $\begin{array}{l}\text { AAFP } 625 \\
34\end{array}$ & $\begin{array}{l}\text { OAA } 1000 \\
33\end{array}$ \\
\hline \multirow[t]{4}{*}{$\mathrm{AUC}_{0-\infty}(\mathrm{ng} \cdot \mathrm{h} / \mathrm{mL})$} & Mean & 112.12 & 438.02 & 473.31 & 453.18 \\
\hline & $\mathrm{SD}$ & 65.94 & 249.43 & 247.19 & 219.07 \\
\hline & $\mathrm{CV} \%$ & 58.81 & 56.94 & 52.23 & 48.34 \\
\hline & Geometric mean & 93.86 & 372.67 & 418.21 & 408.60 \\
\hline \multirow[t]{4}{*}{$\mathrm{AUC}_{0-t}(\mathrm{ng} \cdot \mathrm{h} / \mathrm{mL})$} & Mean & 102.55 & 416.23 & 450.19 & 415.91 \\
\hline & SD & 63.27 & 245.73 & 241.85 & 210.67 \\
\hline & $\mathrm{CV} \%$ & 61.70 & 59.04 & 53.72 & 50.65 \\
\hline & Geometric mean & 84.75 & 350.02 & 394.76 & 372.51 \\
\hline \multirow[t]{4}{*}{$C_{\max }(\mathrm{ng} / \mathrm{mL})$} & Mean & 28.22 & 84.16 & 100.76 & 83.40 \\
\hline & SD & 16.46 & 44.05 & 63.75 & 57.40 \\
\hline & $\mathrm{CV} \%$ & 58.34 & 52.34 & 63.27 & 68.83 \\
\hline & Geometric mean & 23.98 & 73.45 & 84.07 & 70.44 \\
\hline \multirow[t]{3}{*}{$t_{\max }(\mathrm{h})$} & Median & 1.5 & 1.5 & 1.5 & 2 \\
\hline & Minimum & 0.5 & 0.5 & 0.5 & 0.5 \\
\hline & Maximum & 4 & 6 & 4 & 8 \\
\hline \multirow[t]{4}{*}{$t_{1 / 2}(\mathrm{~h})$} & Mean & 7.20 & 14.12 & 14.54 & 20.64 \\
\hline & SD & 3.47 & 6.44 & 5.54 & 9.03 \\
\hline & $\mathrm{CV} \%$ & 48.28 & 45.61 & 38.07 & 43.75 \\
\hline & Geometric mean & 6.27 & 12.59 & 13.63 & 18.77 \\
\hline \multirow[t]{4}{*}{$K_{\mathrm{e}}(/ \mathrm{h})$} & Mean & 0.13 & 0.06 & 0.05 & 0.04 \\
\hline & SD & 0.09 & 0.05 & 0.02 & 0.02 \\
\hline & $\mathrm{CV} \%$ & 65.70 & 71.26 & 36.10 & 46.69 \\
\hline & Geometric mean & 0.11 & 0.06 & 0.05 & 0.04 \\
\hline
\end{tabular}

$\overline{A A F P}$ abiraterone acetate fine particle, $A U C_{O-\infty}$ area under the plasma concentration-time curve from time zero to infinity, $A U C_{O-t}$ area under the plasma concentration-time curve from time zero to the time of the last quantifiable concentration, $C_{\max }$ maximum plasma concentration, $C V \%$ coefficient of variation expressed as percent, $K_{e}$ apparent elimination rate constant, $N$ number of subjects included in the pharmacokinetic population for each treatment, $O A A$ originator abiraterone acetate, $S D$ standard deviation, $t_{1 / 2}$ elimination half-life, $t_{\text {max }}$ time to maximum plasma concentration

a AAFP $125 \mathrm{mg}(1 \times 125 \mathrm{mg}), 500 \mathrm{mg}(4 \times 125 \mathrm{mg}), 625 \mathrm{mg}(5 \times 125 \mathrm{mg})$, and OAA $1000 \mathrm{mg}(4 \times 250 \mathrm{mg})$ under fasted conditions

500-mg dose was bioequivalent to OAA based on the $90 \%$ CI of the geometric mean ratio of AUC and $C_{\max }$ parameters. Pooled pharmacokinetic values for OAA $1000 \mathrm{mg}$ [AUC ${ }_{0-\infty} 503 \mathrm{ng} \cdot \mathrm{h} / \mathrm{mL}$ (SD 299); $C_{\max } 94 \mathrm{ng} / \mathrm{mL}$ (SD 58.6)] [9] from previous clinical trials in healthy subjects were within the range of values for OAA $1000 \mathrm{mg}$ and AAFP $500 \mathrm{mg}$ in this study. Although a large proportion of the study sample was healthy African-American volunteers, racial differences in drug metabolism should not impact our findings because in this crossover study the same subjects received the different dose levels of AAFP and the 1000-mg dose of the reference drug (OAA). Therefore, we do not believe that the comparisons between OAA and the various AAFP doses were affected. In addition, AAFP was safe and well tolerated at all doses tested (100-625 mg), under the conditions of these studies.

Following a single dose of AAFP from 125 to $625 \mathrm{mg}$ under fasted conditions, the median $t_{\max }$ was approximately $1.5 \mathrm{~h}$ post-dose, compared with a median of $2.0 \mathrm{~h}$ for OAA $1000 \mathrm{mg}$, and was in agreement with previously reported $t_{\max }$ for OAA $1000 \mathrm{mg}$ [9]. The mean $t_{1 / 2}$

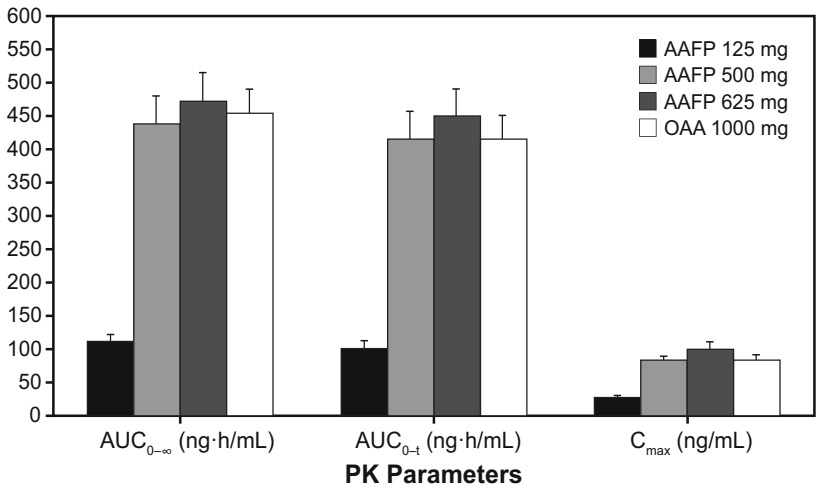

Fig. 2 Mean (standard error) of area under the plasma concentrationtime curve and maximum plasma concentration $\left(C_{\max }\right)$ parameters by treatment for Study 102. AAFP abiraterone acetate fine particle, $A U C_{0-\infty}$ area under the plasma concentration-time curve from time zero to infinity, $A U C_{0-t}$ area under the plasma concentration-time curve from time zero to the time of the last quantifiable concentration, $O A A$ originator abiraterone acetate, $P K$ pharmacokinetic

of abiraterone across the previous clinical studies was $15.2 \mathrm{~h}$, with across-study variation from 12.7 to $19 \mathrm{~h}$ [9]. In healthy subjects under fasted conditions in Study 102, 


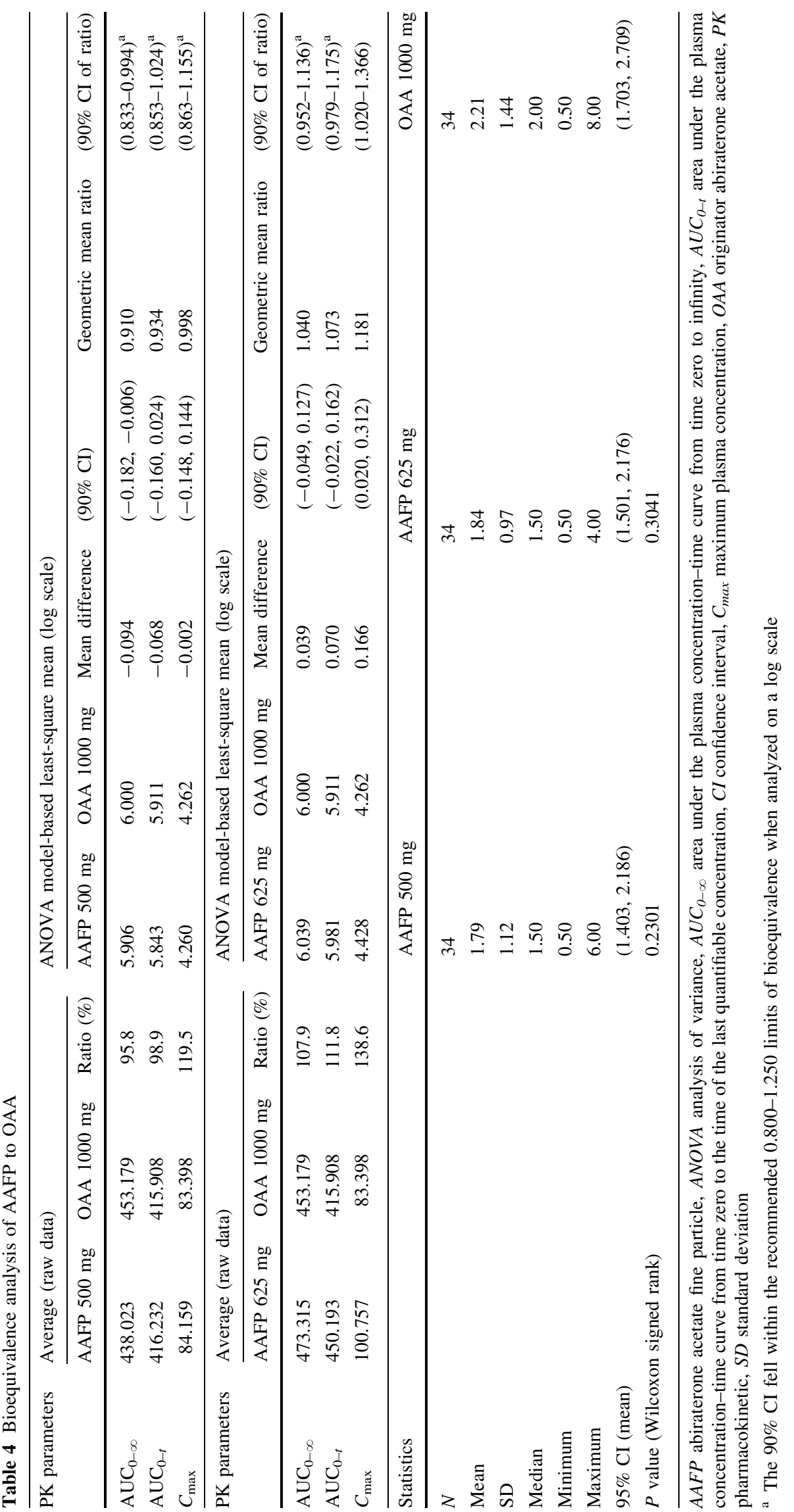


the $t_{1 / 2}$ was $14.1 \mathrm{~h}$ for AAFP $500 \mathrm{mg}$ vs. $20.6 \mathrm{~h}$ for OAA $1000 \mathrm{mg}$, indicating that OAA $1000 \mathrm{mg}$ takes more time to be completely eliminated from the body than AAFP $500 \mathrm{mg}$. At present, the mechanistic basis for the differences in $t_{1 / 2}$ between AAFP and OAA is unknown, because the same healthy subjects within each study crossed over to the different AAFP dose levels and the 1000-mg dose of OAA (the same subjects were given AAFP and OAA).

Absorption is a function of many factors including dissolution rate, site of absorption, gastrointestinal transit time, concentration gradient, presence of food, and dose [10]. Reduced particle size leads to an enhanced surface area, and this in turn leads to an enhanced rate of dissolution and absorption $[11,12]$. The absorption of OAA is reported to be nearly saturated at a dose of $1000 \mathrm{mg}[7,8]$. In contrast, the results with AAFP in the current study show continued increased absorption above a single AAFP 500-mg dose; i.e., at AAFP $625 \mathrm{mg}$. Namely, a single dose of $625 \mathrm{mg}$ of AAFP delivered a higher $C_{\max }$ and AUC than $1000 \mathrm{mg}$ of OAA. Higher levels of absorption with AAFP have the potential for clinical benefit in patients with poor absorption or low or no response to OAA. This warrants further exploration.

SoluMatrix Fine Particle Technology ${ }^{\mathrm{TM}}$ produces drug particles 200-800 $\mathrm{nm}$ in diameter, which increases the drug particle surface area relative to its mass [13]. The manufacturing process, which does not alter the active therapeutic ingredient, was previously shown to promote rapid absorption of new formulations of diclofenac and meloxicam $[11,12]$. The present study in healthy subjects indicates that the use of SoluMatrix Fine Particle Technology ${ }^{\mathrm{TM}}$ enhances the bioavailability of abiraterone acetate. An ongoing study (ClinicalTrials.gov Identifier: NCT02737332) will assess the pharmacokinetics and pharmacodynamics of AAFP $500 \mathrm{mg}$ vs. OAA $1000 \mathrm{mg}$ in patients with metastatic castration-resistant prostate cancer.

The limitations of the study include the single dosing of AAFP and OAA, and the use of healthy volunteers for the analyses. In addition, AAFP and OAA were tested under fasted conditions. A subsequent study will analyze the bioavailability of AAFP under fed vs. fasted conditions.

\section{Conclusion}

A single AAFP 500-mg dose was bioequivalent to OAA $1000 \mathrm{mg}$ in healthy subjects under fasting conditions. Thus, the proprietary AAFP formulation using SoluMatrix Fine Particle Technology ${ }^{\mathrm{TM}}$ allows for the same systemic exposure to be achieved with $50 \%$ less drug relative to the recommended dose of OAA $1000 \mathrm{mg}$. 
Table 6 Power-model analysis of dose proportionality for AAFP doses $(100,125,200$, 400,500 , and $625 \mathrm{mg}$ ) for pooled data from Study 101 and Study 102

\begin{tabular}{|c|c|c|c|}
\hline \multirow[t]{2}{*}{ PK parameters } & \multirow[t]{2}{*}{ Statistics } & \multicolumn{2}{|c|}{ Power model: $P=a \times$ Dose $^{b}$} \\
\hline & & $a$ & $b$ \\
\hline \multirow[t]{4}{*}{$\mathrm{AUC}_{0-\infty}$} & Parameter estimates & 0.7810 & 0.9864 \\
\hline & 95\% CI-lower limit & 0.3891 & 0.8640 \\
\hline & 95\% CI-upper limit & 1.5677 & 1.1089 \\
\hline & $P$ value & 0.4845 & $<0.0001$ \\
\hline \multirow[t]{4}{*}{$\mathrm{AUC}_{0-t}$} & Parameter estimates & 0.6163 & 1.0146 \\
\hline & 95\% CI-lower limit & 0.2994 & 0.8877 \\
\hline & 95\% CI-upper limit & 1.2688 & 1.1415 \\
\hline & $P$ value & 0.1874 & $<0.0001$ \\
\hline \multirow[t]{4}{*}{$C_{\max }$} & Parameter estimates & 0.3304 & 0.8648 \\
\hline & 95\% CI-lower limit & 0.1574 & 0.7345 \\
\hline & 95\% CI-upper limit & 0.6937 & 0.9951 \\
\hline & $P$ value & 0.0037 & $<0.0001$ \\
\hline
\end{tabular}

$A A F P$ abiraterone acetate fine particle, $A U C_{0-\infty}$ area under the plasma concentration-time curve from time zero to infinity, $A U C_{0-t}$ area under the plasma concentration-time curve from time zero to the time of the last quantifiable concentration, $C I$ confidence interval, $C_{\max }$ maximum plasma concentration, $P K$ pharmacokinetic
Acknowledgements The authors thank Yuxin Zhang (Xtiers Consulting, Inc., Potomac, MD, USA) for conducting the statistical analyses and Sharon Reinhard for help with clinical operations. The authors also thank the study participants and the site staff who made this study possible. All listed authors meet the criteria for authorship set forth by the International Committee for Medical Journal Editors. Editorial support (assembling tables and figures, collating author comments, copyediting, fact checking, and referencing) and graphic services were provided by Gautam Bijur, Ph.D., and Nancy Price, Ph.D., of AOI Communications, L.P. and were funded by Churchill Pharmaceuticals LLC.

\section{Compliance with Ethical Standards}

Funding This study was funded by Churchill Pharmaceuticals LLC.

Conflict of interest Bill Bosch and Paul Nemeth are employees of Churchill Pharmaceuticals LLC. Azra Hussaini and Ronald Goldwater are employees of PAREXEL Early Phase Clinical Unit, which received funding from Churchill Pharmaceuticals LLC to conduct the clinical study.

Ethics approval All procedures performed in studies involving human participants were in accordance with the ethical standards of the institutional and/or national research committee and with the 1964 Helsinki Declaration and its later amendments or comparable ethical standards. The Dose Finding Study 101 and Bioavailability Study 102 were conducted in compliance with the International Conference on Harmonisation Good Clinical Practice guidelines. The study was approved by the Aspire Institutional Review Board (Santee, CA, USA).

Consent to participate All subjects provided written informed consent before study procedures were initiated.

Open Access This article is distributed under the terms of the Creative Commons Attribution-NonCommercial 4.0 International License (http://creativecommons.org/licenses/by-nc/4.0/), which permits any noncommercial use, distribution, and reproduction in any medium, provided you give appropriate credit to the original author(s) and the source, provide a link to the Creative Commons license, and indicate if changes were made.

\section{References}

1. International Agency for Research on Cancer. GLOBOCAN cancer fact sheets: prostate cancer. 2016. http://globocan.iarc.fr/ Pages/fact_sheets_cancer.aspx. Accessed 23 Sept 2016.

2. Siegel RL, Miller KD, Jemal A. Cancer statistics, 2016. CA Cancer J Clin. 2016;66(1):7-30.

3. Gomez L, Kovac JR, Lamb DJ. CYP17A1 inhibitors in castration-resistant prostate cancer. Steroids. 2015;95:80-7.

4. Nussbaum N, George DJ, Abernethy AP, et al. Patient experience in the treatment of metastatic castration-resistant prostate cancer: state of the science. Prostate Cancer Prostatic Dis. 2016;19(2):111-21.

5. Reid AH, Attard G, Barrie E, de Bono JS. CYP17 inhibition as a hormonal strategy for prostate cancer. Nat Clin Pract Urol. 2008;5(11):610-20.

6. Attard G, Reid AH, Yap TA, et al. Phase I clinical trial of a selective inhibitor of CYP17, abiraterone acetate, confirms that castration-resistant prostate cancer commonly remains hormone driven. J Clin Oncol. 2008;26(28):4563-71.

7. Janssen Biotech Inc. Zytiga ${ }^{\circledR}$ (abiraterone acetate) tablets. 2016. https://www.zytigahcp.com/shared/product/zytiga/zytiga-prescribinginformation.pdf. Accessed 16 Sept 2016.

8. European Medicines Agency. Assessment report for Zytiga (abiraterone). 2011. http://www.ema.europa.eu/docs/en_GB/ document_library/EPAR_-_Public_assessment_report/human/ 002321/WC500112860.pdf. Accessed 16 Sept 2016.

9. Center for Drug Evaluation and Research. Clinical pharmacology and biopharmaceutics review(s): application number: 2023790rig1s000. Zytiga. 2010. http://www.accessdata.fda.gov/ drugsatfda_docs/nda/2011/202379Orig1s000ClinPharmR.pdf. Accessed 16 Sept 2016. 
10. Martinez MN, Amidon GL. A mechanistic approach to understanding the factors affecting drug absorption: a review of fundamentals. J Clin Pharmacol. 2002;42(6):620-43.

11. Desjardins PJ, Olugemo K, Solorio D, Young CL. Pharmacokinetic properties and tolerability of low-dose SoluMatrix diclofenac. Clin Ther. 2015;37(2):448-61.
12. Hussaini A, Solorio D, Young C. Pharmacokinetic properties of low-dose SoluMatrix meloxicam in healthy adults. Clin Rheumatol. 2016;35(4):1099-104.

13. Altman R, Bosch B, Brune $\mathrm{K}$, et al. Advances in NSAID development: evolution of diclofenac products using pharmaceutical technology. Drugs. 2015;75(8):859-77. 